\title{
Evaluating community-facility linkage models to promote mother- infant retention along the HIV care continuum
}

Project SOAR

Follow this and additional works at: https://knowledgecommons.popcouncil.org/departments_sbsr-hiv

Part of the Demography, Population, and Ecology Commons, Family, Life Course, and Society Commons, International Public Health Commons, Maternal and Child Health Commons, Medicine and Health Commons, and the Women's Health Commons How does access to this work benefit you? Let us know!

\section{Recommended Citation}

Project SOAR. 2017. "Evaluating community-facility linkage models to promote mother-infant retention along the HIV care continuum," Activity brief. Washington, DC: Population Council. 


\section{Evaluating Community-facility Linkage Models to Promote Mother-infant Retention Along the HIV Care Continuum}

Despite the impressive maternal and child health gains achieved by the Option B+ and test and start strategies in Malawi, client attrition along the prevention of mother-to-child transmission (PMTCT) care continuum threatens recent progress. As many as 15 percent of HIV-positive pregnant women do not start antiretroviral treatment (ART), ${ }^{1}$ and another 31 percent become lost to follow-up within 12 months of treatment initiation. ${ }^{2}$ Similarly, high loss to follow-up is seen among HIV-exposed infants and young children. Such mother-infant pair (MIP) drop-out from the PMTCT care continuum has deleterious "downstream" effects, including higher vertical transmission rates and worse clinical outcomes for HIV-positive mothers and HIV-exposed infants alike. $^{3}$

In Malawi, and other resourced-constrained, subSaharan African countries with a high HIV burden,

Research Partners: University of North Carolina, Partners in Health, Malawi Ministry of Health, and UNICEF

Location: Five districts from Northern, Central and Southern Malawi (Mzimba South, Dedza, Lilongwe, Neno and Zomba)

Study Duration: 2016-2019

For more information, contact Michael Herce (michael_herce@ med.unc.edu), Joseph Njala (jnjala@unclilongwe.org), and Innocent Mofolo (imofolo@ unclilongwe.org).

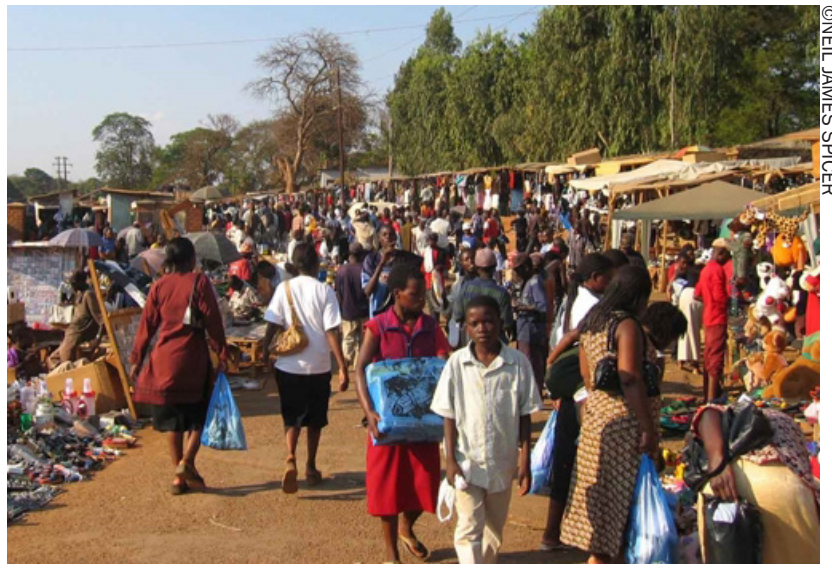

Study findings will help decision-makers refine and accelerate scale up of promising CFL practices in Malawi and elsewhere in the region

several service delivery models have emerged to increase PMTCT care retention by strengthening connections between health facilities and their surrounding communities. Yet there has been little documentation of the unique characteristics of each model and their comparative impact on MIP care retention and other health outcomes.

Project SOAR is responding to these knowledge gaps by conducting research to identify components of community-based MIP support that are associated with maternal care retention and infant HIV-free survival. This will help decision-makers refine and accelerate scale up of promising community-facility linkage (CFL) practices in Malawi and elsewhere in the region.

\section{Our Research}

Project SOAR is using a mixed method approach, involving both quantitative and qualitative data collection to: 
- Establish a clear typology for CFL models by describing the main components of and the perspectives of key stakeholders (e.g., community-based service providers, Ministry of Health workers, and HIV-positive mothers) on three such models in Malawi.

- Describe MIP health outcomes in each model, and compare outcomes across models and versus the standard of care by:

- Determining individual-level outcomes for a retrospective cohort comprised of all mothers who newly enrolled in the national PMTCT program in 2016 across 40 randomly selected health facilities and their surrounding communities in 5 representative districts of Malawi.

- Prospectively ascertaining MIP vital status, maternal viral load, and infant HIV status from a randomly selected nested sample of 1,600 MIPs from our 2016 cohort.

\section{Research Utilization}

The primary audiences for results dissemination and utilization are policy makers and program managers working on PMTCT programs in Malawi and elsewhere in sub-Saharan Africa. We will convene a study advisory committee to provide guidance and strategic recommendations throughout the course of the study on 1) study operations to meet the study objectives; 2) results dissemination and stakeholder/community engagement; 3) data analyses and possible substudies; and 4) the inclusion of relevant lessons learned into district, national, and regional policy.

We will share interim and final results with the United States Agency for International Development, Government of Malawi, and other stakeholders at the district and community levels. As part of our final results dissemination, we will hold a national-level meeting with key stakeholders who will help interpret the results and develop action plans on how the results can be used in their respective programmatic and policy areas.
Which CFL models are being evaluated? The models utilize either 1) facility-based mentor mothers; 2) community-based expert clients; or 3) community health workers (CHWs).

Mentor mothers and expert clients are types of peer health workers-women living with HIV who offer health education and psychosocial support, often via peer group meetings, to PMTCT clients.

CHWs are lay health workers who provide clients with psychosocial support, promote medication and appointment attendance, accompany clients to health facilities, and support the services provided by other health workers.

All three models trace HIV-positive women who fall out of care by having a CFL mentor mother, expert mother, or $\mathrm{CHW}$ encourage women by phone or through home visits to return to the clinic with their infants.

\section{References}

${ }^{1}$ Tenthani, L. et al. 2014. "Retention in care under universal antiretroviral therapy for HIV-infected pregnant and breastfeeding women ('Option B+') in Malawi," AIDS 28(4): 589-598.

${ }^{2} \mathrm{MOH} .2016$. Integrated HIV Program Report JanuaryMarch 2016. Government of Malawi, Ministry of Health, 2016.

${ }^{3}$ Barker, P. M., W. Mphatswe, and N. Rollins. 2011. "Antiretroviral drugs in the cupboard are not enough: the impact of health systems' performance on motherto-child transmission of HIV," Journal of Acquired Immune Deficiency Syndromes 56(2): e45-48. agreement funded by the President's Emergency Plan for AIDS Relief and the U. S. Agency for International Development (Agreement No. AIDOAA-A-14-00060). SOAR is able to accept funding from all USAID accounts.
Project SOAR/Population Council

4301 Connecticut Avenue, NW, Suite 280

Washington, DC 20008

Tel: +12022379400

e-mail: ProjectSOAR@popcouncil.org

popcouncil.org/ProjectSOAR

(C)Population Council, June 2017 